\title{
Two cases of laboratory-confirmed leptospirosis in travellers returning to Spain from Thailand, September 2013
}

A Calvo-Cano (ancalvo@clinic.ub.es) ${ }^{1}$, E Aldasoro ${ }^{1}$, M F Ramírez $^{2}$, M J Martínez $^{3}$, A Requena-Méndez ${ }^{1}$, Gascon ${ }^{1}$

1. International Health and Tropical Medicine Department, Barcelona Centre for International Health Research (CRESIB), Hospital Clínic-Universitat de Barcelona, Barcelona, Spain

2. Internal Medicine Department, Hospital Universitari Lleida, Lleida, Spain

3. Microbiology Laboratory, Barcelona Centre for International Health Research

Citation style for this article:

Calvo-Cano A, Aldasoro E, Ramírez MF, Martínez MJ, Requena-Méndez A, Gascon J. Two cases of laboratory-confirmed leptospirosis in travellers returning to Spain from Thailand, September 2013. Euro Surveill. 2014;19(2):pii=20675. Available online: http://www.eurosurveillance.org/ViewArticle.aspx?Articleld=20675

Article submitted on 03 January 2014 / published on 16 January 2014

In September 2013, leptospirosis was diagnosed in two Spanish travellers returning from Thailand. The first case walked in floodwater in the Phi Phi Islands in pouring rain: 20 days later he presented with fever and acute hepatitis. The second presented with fever and renal failure 17 days after visiting the islands. These cases remind clinicians to consider leptospirosis in febrile patients with a history of contact with flood or fresh water while travelling to tropical countries.

We report on two patients diagnosed in September 2013 with leptospirosis following travel to Thailand. They also act as a reminder for clinicians to consider leptospirosis in the differential diagnosis of febrile patients with a history of contact with flood or fresh water while travelling to tropical countries.

\section{Case 1}

In August 2013, a Spanish man in his early 30 s spent 13 days as a tourist in Thailand. He visited the Phi Phi Islands on 8 August, in the pouring rain. While walking there that day, sewers were overflowing and despite his efforts, his feet came into contact with waste water. Back in Spain, 20 days after this incident, he presented with high fever $\left(38.6^{\circ} \mathrm{C}\right)$, malaise, myalgia and mild headache. Five days later, he consulted at our outpatient department (Tropical Medicine Department) at the Hospital Clínic in Barcelona, Spain. After a negative thick smear, pending results of arbovirus serology and blood cultures, he received azithromycin in case he had typhoid fever. Afebrile three days later, conjunctival suffusion and painful hepatomegaly was noted on physical examination.

Laboratory results showed a raised level of C-reactive protein $(17.65 \mathrm{mg} / \mathrm{dL}$, norm: $\ll 1 \mathrm{mg} / \mathrm{dL})$, relative neutrophilia and a marked increase in the level of liver transaminases (alanine transaminase (ALT): $452 \mathrm{U} / \mathrm{L}$, aspartate transaminase (AST): $313 \mathrm{U} / \mathrm{L}$, gamma-glutamyltransferase (GGT): $223 \mathrm{U} / \mathrm{L}$, the norm for all three being 5-40 U/L; alkaline phosphatase: $395 \mathrm{U} / \mathrm{L}$, norm: 80-240 U/L). Bilirubin level and renal function were normal.

Leptospira infection was confirmed by microscopic agglutination test (MAT), titre 1:160 (sample on 8th day of illness) and 1:2,560 (25th day). The causative serovar identified by MAT was canicola. We also tested for hepatitis $A$ and hepatitis $E$ virus infection serologically: both results were negative. Other differential diagnoses such as dengue and chikungunya were also excluded by serological tests. Blood cultures remained negative. Liver function recovered completely after one month of follow-up. His fellow traveller (his partner) remained asymptomatic.

\section{Case 2}

In September 2013, a Spanish man in his early $40 \mathrm{~S}$ spent 14 days as a tourist in Thailand. He had a history of traumatic bile duct injury. He visited the Phi Phi Islands on 10 September, it was not raining, but the ground was wet. He also canoed in Ping River, in Chiang Mai province on 17 September, and stayed on a beach that had many rats on the island of Phuket, where he ate some food from street vendors. Seven days after his return to Spain (17 and 10 days after his visit to the Phi Phi Islands and his canoeing, respectively), he presented with high fever $\left(39.5{ }^{\circ} \mathrm{C}\right)$, chills and headache at the emergency department of the Hospital Clínic in Barcelona. After a negative thick smear, pending results of arbovirus serology and blood cultures, intravenous ceftriaxone and doxycycline were administered. Physical examination was normal, except for high fever.

Laboratory results showed a raised level of C-reactive protein $(23.9 \mathrm{mg} / \mathrm{dL})$, leucocytosis and neutrophilia, a mild increase in the level of liver transaminases (AST: $57 \mathrm{U} / \mathrm{L}, \mathrm{ALT}: 74 \mathrm{U} / \mathrm{L}$ ) and a progressive renal impairment (maximum creatinine level of $4.01 \mathrm{mg} / \mathrm{dL}$, norm: $0.3-1.3$ 
$\mathrm{mg} / \mathrm{dL}$ ). On admission, he received vigorous intravenous hydration until kidney function was restored. MAT showed a titre of 1:640 (7th day of illness) and 1:2,560 (23th day), confirming Leptospira interrogans infection, but the serovar could not be reliably identified. Blood cultures and dengue and chikungunya serology remained negative. His fellow traveller presented nonspecific respiratory symptoms, but leptospirosis was excluded due to a negative MAT result.

\section{Background}

Leptospirosis is a worldwide zoonosis of great public health importance in the tropics, where large outbreaks have occurred. Animals infected with the spirochetes of the genus Leptospira - of which there are more than 200 known serovars - shed the bacteria through their urine intermittently or continuously throughout their lives. The disease is caused in humans either through direct contact with infected animals or through contact with urine in the environment from an infected animal. After the incubation period (2-28 days), it often presents as a self-limiting influenza-like illness. Sometimes patients develop serious complications: kidney or liver failure, pulmonary haemorrhage, myocarditis or meningitis. Penicillin, doxycycline, ceftriaxone or azithromycin are the preferred therapeutic drugs [1].

\section{Differential diagnosis}

Leptospira can be cultured; although molecular techniques are being explored, the widely available diagnostic tests are based on serology [2]. The disease is mandatorily reportable in the European Union (EU) and we follow the EU case definition [3]. Leptospirosis is, however, a diagnostic challenge because the clinical picture mimics many febrile (tropical) infections. The first case's illness was less severe and he was managed as an outpatient. The incubation period (20 days) was too long for an arbovirus infection. Plasmodium infection was excluded by a negative blood smear and the patient was treated for possible typhoid and paratyphoid fever. As the patient had conjunctival suffusion and liver involvement at the time of their second visit to the hospital, we considered leptospirosis and viral hepatitis A, although dissociated cholestasis is not typical of either. We also excluded hepatitis $E$ with negative serology, as there are reports of coinfections [4].

The second case was admitted to hospital and required close monitoring during the first 48 hours due to renal impairment, worsening general condition and signs of bacteraemia. Having dismissed malaria, we empirically treated enteric fever and also rickettsiosis. Renal failure and a history of having visited the Phi Phi Islands, as the first patient had, led us to suspect Leptospira infection.

\section{Potential risk factors}

In Spain, leptospirosis has traditionally been an occupational illness (rice farming). According to the latest annual epidemiological report from the European Centre for Disease Prevention and Control, in 2011, there were 526 confirmed cases of leptospirosis at the EU level: of these, four were from Spain, none of which were travel related [5]. The estimated incidence in Thailand in 2013 was 4.58 per 100,000 population: that year, a total of 2,908 cases were reported, with 29 deaths [6]. A review of imported diseases in Europe during 15 years of follow-up (1996 to 2011) showed 88 cases [7]. Estimated high-risk areas were south-east Asia $55.6 \%$, i.e. calculated as the number of cases imported from each area/total number of imported cases $(n=88)$ ), central America $(17 \%)$ and the Caribbean (8\%) [7]. Leptospirosis is increasingly seen in returning travellers [8], mainly due to an increase in the number of people who participate in outdoor recreational activities [9]. Other described risk factors are accidental submersion in potentially contaminated fresh water [10] and travelling in periods of excess rainfall [11]. During such periods in tropical countries, the soil turns into a warm and humid environment, optimum for the growth of leptospires, where they can survive for one to two months [12]. The two cases reported here following travel to Thailand may have been infected from the same source (rainwater on the Phi Phi Islands); however, for Case 2, canoeing in the Chang-Mai province could also have presented a risk, particularly if the case fell into the water.

\section{Conclusion}

A reporting system that facilitates the identification of potential sources of Leptospira infection in returning travellers could be useful. Surveillance of imported cases contributes to a better estimation of the incidence of the disease in the country visited and to an early identification of clusters. Moreover, such a reporting system would benefit both public health and clinical management: awareness of the risk factors for leptospirosis would potentially help to lead to an early diagnosis and prompt treatment of this potentially lethal disease.

\section{Acknowledgments}

The research of the authors are supported by the grant 2009SGR385 from the Departament d'Universitats i Recerca de la Generalitat de Catalunya (AGAUR).

\section{Conflict of interest}

None declared

Authors' contributions

Antonia Calvo-Cano, Edelweiss Aldasoro and Maria Fernanda Ramírez were the reference clinicians attending the patient. Miguel J. Martinez was the microbiologist who performed the serological tests. Ana Requena-Méndez and Joaquim Gascon collaborated in clinical follow-up of the patients. Antonia Calvo-Cano and Joaquim Gascon wrote the manuscript. All authors read and approved the final manuscript. 


\section{References}

1. Mandell G, Bennett J, Dolin R. Mandell, Douglas and Bennett's principles and practice of infectious diseases. 7 th ed. Volume 2. Philadelphia, PA: Churchill Livingstone Elsevier; 2010.

2. M Picardieau. Diagnosis and epidemiology of leptospirosis. Med Mal Infect. 2013;43(1):1-9. http://dx.doi.org/10.1016/j. medmal.2012.11.005

3. European Commission. Commission decision of 28 April 2008 amending Decision 2002/253/EC laying down case definitions for reporting communicable diseases to the Community network under Decision No 2119/98/EC of the European Parliament and of the Council. Official Journal of the European Union. Luxembourg: Publications Office of the European Union. 18.6.2008: L 159/46. Available from: http://eur-lex.europa.eu/ LexUriServ/LexUriServ.do?uri=0]:L:2008:159:0046:0090:EN: PDF

4. Chaudhry R, Das A, Premlatha MM, Choudhary A, Chourasia BK, Chandel DS, et al. Serological \& molecular approaches for diagnosis of leptospirosis in a tertiary care hospital in north India: a 10-year study. Indian J Med Res. 2013;137(4):785-90.

5. European Centre for Disease Prevention and Control (ECDC). Annual epidemiological report 2013. Reporting on 2011 surveillance data and 2012 epidemic intelligence data. Stockholm: ECDC; 2013. Available from: http://www. ecdc.europa.eu/en/publications/Publications/annualepidemiological-report-2013.pdf

6. Bureau of Epidemiology, Ministry of Public Health (MoPH), Thailand. Leptospirosis. National disease surveillance (Report 506). Nonthaburi: MoPH; 2013. http://www.boe.moph.go.th/ boedb/surdata/506wk/y56/en/d43_5156_en.pdf

7. Jensenius M, Han PV, Schlagenhauf P, Schwartz E, Parola P, Castelli $F$, et al. Acute and potentially life-threatening tropical diseases in western travellers--a GeoSentinel multicenter study, 1996-2011. Am J Trop Med Hyg. 2013;88(2):397-404. http://dx.doi.org/10.4269/ajtmh.12-0551

8. Lau C, Smythe L, Weinstein P. Leptospirosis: an emerging disease in travellers. Travel Med Infect Dis. 2010;8(1):33-9. http://dx.doi.org/10.1016/j.tmaid.2009.12.002

9. van de Werve $C$, Perignon A, Jauréguiberry S, Bricaire F, Bourhy P, Caumes E. Travel-related leptospirosis: a series of 15 imported cases. J Travel Med. 2013;20(4):228-31. http://dx.doi. org/10.1111/jtm.12035

10. Arcilla M, Wismans PJ, van Beek-Nieuwland Y, van Genderen PJ. Severe leptospirosis in a Dutch traveller returning from the Dominican Republic, October 2011. Euro Surveill. 2012;17(13):pii=20134. Available from: http://www. eurosurveillance.org/ViewArticle.aspx?Articleld=20134

11. Chadsuthi S, Modchang C, Lenbury Y, Iamsirithaworn S, Triampo W. Modeling seasonal leptospirosis transmission and its association with rainfall and temperature in Thailand using time-series and ARIMAX analyses. Asian Pac J Trop Med. 2012;5(7):539-46. http://dx.doi.org/10.1016/ S1995-7645(12)60095-9

12. Desvars A, Jégo S, Chiroleu F, Bourhy P, Cardinale E, Michault A. Seasonality of human leptospirosis in Reunion Island (Indian Ocean) and its association with meteorological data. PLoS One. 2011;6(5):e20377. http://dx.doi.org/10.1371/journal. pone.0020377 